\title{
Cellular Senescence as a Barrier to Environmental Carcinogenesis
}

\author{
Maria del Mar Vergel and Amancio Carnero* \\ Institute of Biomedicine of Seville (IBIS), HUVR/ consejo Superior de Investigaciones Cientiticas (CSIC)
}

\begin{abstract}
The first cellular response to a carcinogen is a cell cycle arrest program that may end in a permanent arrest with features of cellular senescence. This may be an evolutionary conserved response to delay environmental-induced cancer until the replicative life of the organism has ended. With the concomitant alteration of genes involved in cellular senescence, which promotes cellular immortalization, a further carcinogenic insult may increase the chances of tumorigenesis and the development of a malignant clone. Therefore, understanding cellular senescence and how it can be modified by environmental carcinogens, including food, may be essential for controlling the increase of cancer prevalence.
\end{abstract}

Keywords: Cellular senescence; Cancer; Environmental carcinogenesis

\section{Carcinogenesis}

Carcinogens are widespread in nature. Humans and animals have been exposed to carcinogens for millions of years, both those in the external environment, including food, and those generated endogenously. It has been estimated that $80-90 \%$ of human tumors are generated by exposure to carcinogens, both environmental (chemicals, viruses, and non-ionizing and ionizing radiation) and endogenous (including reactive oxygen species from metabolism) [1,2].

Cancer development in humans and animals as a result of environmental factors, chemicals, viruses, radiation, and diet is a long process, requiring a large portion (from a third to half) of the lifespan of the organism [1,2]. There have been many hypotheses to explain this delayed carcinogenic effect, including the dominant role for immunological surveillance, first suggested by Thomas in 1959 $[3,4]$, and tumor dormancy [5]. It is now understood that several mutations need to accumulate in different hallmarks to result in a full tumorigenic phenotype, including mutations responsible for avoiding immunological surveillance [6,7]. Initiation with one of many different carcinogens should be followed by the spontaneous or autonomous proliferation of cells intended to form a tumor. However, the autonomous or semiautonomous growth of initiated cells only occurs late in the carcinogenic process. Focal lesions with autonomous cell proliferation can only be observed after large doses of carcinogens and much longer periods of exposure than that required for initiation. In fact, virtually every chemical carcinogen is an inhibitor of cell proliferation $[8,9]$. Haddow has suggested that the inhibition of cell proliferation could be an early effect of carcinogens and that in such an environment, resistant cells might arise and be encouraged to proliferate [10]. The growth of rare altered cells leading to focal neoplasms is a key phenomenon in the promotion of cancer development in virtually all experimental carcinogenesis models and in many human systems $[1,6]$.

In most instances of cancer development in humans or animals in which a precursor cell population or a lesion has been identified or proposed, the "preneoplastic" and "precancerous" changes are always focal and often clonal, involving only a very small number of altered cells $[1,11,12]$.

Different chemical agents, both mutagens and non-mutagens, have been shown to induce cellular senescence. Treatment of primary cells with high doses of radiation and other DNA-damaging agents results in senescence [13]. Similar effects were obtained after treatment with
$\mathrm{H} 2 \mathrm{O} 2$ or other reactive oxygen species [13-16]. Interestingly, the treatment of various tumor cell lines with different chemotherapeutic agents, radiation, or differentiating agents also induces irreversible growth arrest, with features similar to cellular senescence [17]. Moderate doses of doxorubicin induced a senescent phenotype in 11 out of 14 tumor cell lines, independent of p53 status [18]. A similar effect has been observed in cell lines derived from human tumors treated with cisplatin [19], hydroxyurea [20] and bromodeoxyuridine [21] which are all DNA-damaging agents. The propensity of tumor cells to undergo senescence in response damage induced by commonly used chemicals was compared in cell lines with various origins [17]. Under equitoxic doses, the strongest induction of a senescent phenotype was observed with DNA-interacting agents (doxorubicin, aphidicolin, and cisplatin) and the weakest effect was observed with microtubule-targeting drugs (taxol and vincristine). A moderate response was observed with ionizing radiation, cytarabine, and etoposide. The induction of senescence by the drugs was dose dependent and correlated with the growth arrest observed in culture [13,20-22]. Drug-induced senescent phenotypes have been confirmed in vivo ([23-25] and references therein).

Since the early 80 s and the seminal work of Newbold et al. [26,27], cellular senescence has been viewed as a barrier to tumorigenesis. These and other authors have shown that it is necessary to bypass senescence to initiate immortal and/or tumoral clones from a naïve culture. They estimated that the efficacy of carcinogens that produced these clones was greatly increased (Table 1).

However, despite the highly increased ratio of immortalization, the vast majority of cells remain non-proliferative, and they most probably have entered carcinogenic-induced senescence. The molecular analysis of immortal clones shows alterations, either structural or epigenetic, in the genes involved in cellular senescence [28-34]. It is thought that these alterations are caused directly by carcinogens. This may lead to biased

*Corresponding author: Amancio Carnero, Institute of Biomedicine of Sevilla, Virgen del Rocio University Hospital, Building IBIS, Manuel Siurot s/n.41013, Sevilla, Spain, Tel: 95592 3111; E-mail: acarnero-ibis@us.es

Received December 05, 2013; Accepted January 13, 2014; Published January 19, 2014

Citation: Vergel MDM, Carnero A (2014) Cellular Senescence as a Barrier to Environmental Carcinogenesis. J Carcinog Mutagen S3: 004. doi:10.4172/21572518.S3-004

Copyright: (C) 2014 Vergel MDM, et al. This is an open-access article distributed under the terms of the Creative Commons Attribution License, which permits unrestricted use, distribution, and reproduction in any medium, provided the original author and source are credited. 


\begin{tabular}{|l|c|c|}
\hline Species & Spontaneous & Carcinogen exposure $^{\star}$ \\
\hline Human & $10^{-10}$ & $10^{-6 /-7}$ \\
\hline Mouse & $10^{-5}$ & $10^{-3 /-4}$ \\
\hline Rat & $10^{-6}$ & $10^{-4}$ \\
\hline Syrian hamster & $10^{-9}$ & $10^{-6 /-7}$ \\
\hline Chinese hamster & $10^{-6}$ & $10^{-4}$ \\
\hline
\end{tabular}

Table 1: Relative propensities of fibroblasts from different mammalian species to spontaneous- or carcinogen-induced immortalization.

'The efficacy of carcinogen-induced immortalization is dependent on the specific carcinogen and the doses. Here, an estimation of immortalization efficacy for a variety of carcinogens and doses is provided.

\begin{tabular}{|l|c|c|c|}
\hline Agent & Mechan $^{\text {TM }}$ ism & Cell type & Reference \\
\hline lonizing radiation & $\begin{array}{c}\text { DNA-Damage } \\
\text { Oxidative stress }\end{array}$ & $\begin{array}{c}\text { Primary, } \\
\text { Tumor cells }\end{array}$ & {$[18,30]$} \\
\hline $\mathrm{H}_{2} \mathrm{O}_{2}$ & Oxidative stress & Primary & {$[31]$} \\
\hline $\mathrm{Na}$ Butirate & Epigenetic silencing & $\begin{array}{c}\text { Primary, } \\
\text { Tumor cells }\end{array}$ & {$[32]$} \\
\hline $\begin{array}{l}\text { Cisplatin, doxorubicin, } \\
\text { aphidicolin, etoposide, } \\
\text { citarabine, BrDU }\end{array}$ & $\begin{array}{c}\text { DNA-damage } \\
\text { Oxidative stress }\end{array}$ & $\begin{array}{c}\text { Primary, } \\
\text { Tumor cells }\end{array}$ & $\begin{array}{c}{[18]} \\
{[30,23]}\end{array}$ \\
\hline Retinoids & Differentiating agent & $\begin{array}{c}\text { Primary, } \\
\text { Tumor cells }\end{array}$ & {$[33,34]$} \\
\hline Taxol, vincristine & Microtubule targeting & $\begin{array}{c}\text { Primary, } \\
\text { Tumor cells }\end{array}$ & {$[18,30]$} \\
\hline
\end{tabular}

Table 2: Agents inducing senescence.

identification. Only carcinogens able to alter cellular proliferation in parallel with causing immortalization will produce tumors which include unspecific mutagens or genome epigenetic modifiers.

Thus, it seems that the first response to a "mutagenic stress" may be the induction of cellular senescence. The cell becomes immortal only when this physiological barrier is inactivated and then a focal clone that can give rise to a tumor is initiated. We can speculate that cellular senescence is an evolutionary barrier developed to delay environmentally induced tumorigenesis until the replicative lifespan of the individual has ended.

We can suggest, therefore, that cellular senescence is the first response to environmental carcinogens. We also argue that inhibition of such cellular senescence process will trigger a much higher immortalization effect, and therefore carcinogenic, for many environmental carcinogens. As mentioned above, many agents acting on diverse mechanisms have been reported to act inducing senescence in a variety of cell types (Table 2).

\section{Cellular Senescence}

Cellular senescence is a unique state of irreversible proliferative quiescence and terminal differentiation and is characterized by changes in transcription, chromatin conformation, cytoplasmic and nuclear morphology, and DNA damage signaling and a strong increase in the secretion of pro-inflammatory cytokines [35-37]. Senescence is the first line of defense against potentially transformed cells that remain in a state of permanent proliferative stop [30,38,39]. Progression to malignancy correlates with a bypass of cellular senescence [40]. Senescence has been observed in vitro and in vivo in response to various stimuli, including oncogenic stress [41,42], oxidative stress [43], and chemotherapeutic agents $[17,25]$. Cells with cellular and molecular characteristics of senescence have been found to be associated with the activation of oncogenes and the inactivation of tumor suppressor genes in precancerous benign neoplasms in both humans and in animal models [44-47]. For example, human nevis are clonal neoplasms containing benign melanocytes senescent through activation of the oncogene B-RAF [46]. In some mouse models, the inactivation of senescence effectors in parallel to oncogenic activation results in cancerous growth progression instead of benign tumors $[24,44,48,49]$. Senescence activation can be considered to be a cellular response to cell damage and is an attempt to address impaired tissue homeostasis. Thus, senescence inhibits the activation of the tumorigenesis process [39]. The pathways involved in cellular senescence exhibit several levels of regulation with redundancy between the different levels. Moreover, signal transduction through canonical signaling pathways, additional layers of regulation by miRNAs and methylation have been recently discovered [50,51]. The shortening of telomeres has been proposed to be the "clock" responsible for counting divisions in human cells and limits the number of duplications [52]. In general, most tumors contain telomeres elongated by telomerase activity, which allows the constitutive elongation of telomeres. Telomerase activity is essential for replicative immortality in humans but not in most murine models [42]. Cellular senescence can also be elicited by other types of stress, including oncogenic, redox, and DNA-damage stresses, but in these cases, the establishment of cellular senescence is also independent of telomerase [53].

Senescence dynamics show two different stages: cell cycle arrest and the subsequent acquisition of senescence characteristics, including proliferative permanent arrest (geroconversion). Senescence effector pathways converge to cell cycle arrest through the inhibition of CDKs. Therefore, most of the pathways that are known to influence senescence affect the cell cycle, either directly or indirectly. The best known effector pathways are the p16INK4a/pRB, the p19ARF/p53/ p21CIP1, and the PI3K/mTOR/FOXO pathways [54-57], which show a high degree of interconnection. Additionally, two routes have been proposed to be responsible for geroconversion. These include the $\mathrm{pRb}$ pathway and the mTOR pathway [58-62]. If the senescence program is not activated, the cell stops proliferating but retains the ability to resume growth once the limiting factors have been eliminated $[58,59]$. It has also been shown that if the mTOR pathway is activated, arrest is permanent and the cell enters senescence [63]. This can also be achieved by producing permanent changes in chromatin, especially in E2F transcription sites, which block the transcription of genes involved in proliferation [64]. Permanent inactivation of $p R b$, perhaps with the contribution of phosphatases [61] has been shown to give the signal for the recruitment of different mufflers to heterochromatin. Human cells show heterochromatin compaction during senescence (SAHF, senescence associated heterochromatin foci dependent of the $\mathrm{pRb}$ pathway) [64]. These SAHFs stabilize gene silencing, cause cell cycle arrest and appear to be crucial for the stability of the permanent stop during senescence. Mutations in these effector pathways extend the cellular lifespan and contribute to immortality in tumors.

Genetic experiments have contributed to understanding why oncogenic signals need to bypass this barrier to induce tumors and have identified which proteins may be involved in immortalization $[6,43,65]$. The absence of p53 function induced by dominant negative mutants, specific p53 shRNAs, antisense mRNA, oligonucleotides, or viral oncoproteins (such as SV40 T antigen or HPV16 E6) is sufficient to substantially extend the lifespan of several cell types in culture [66-68]. Likewise, the alteration of p53regulators may extend the lifespan to an extent similar to 553 loss. p33ING1, MDM2, p14ARF, the PML tumor suppressor, and the cyclin-dependent kinase (CDK) inhibitor p21WAF1 have been related to $\mathrm{p} 53$, and their alterations bypass senescence (see [66-68] and references therein). The retinoblastoma tumor suppressor pathway, pRb, and its regulators have also been related to senescence. 
Citation: Vergel MDM, Carnero A (2014) Cellular Senescence as a Barrier to Environmental Carcinogenesis. J Carcinog Mutagen S3: 004. doi:10.4172/2157-2518.S3-004

CDK inhibitors, such as the INK4 family, E2F factor, BMI1, PP1a, Spn, and TBX2, and viral oncoproteins, such as E7, SV40 large T antigen, and E1A, have been shown to contribute to senescence $[35,69,70]$. Other pathways such as the $\mathrm{PI} 3 \mathrm{~K} / \mathrm{FoxO} / \mathrm{mTOR}$ pathway also have been strongly related to cellular senescence and with aging in many species $[58,59,71,72]$. A variety of models have been used to identify and study senescence/immortalization genes and pathways. To that end, the application of functional screenings to mammalian cells undergoing senescence has led to the identification of new regulatory pathways impinging on new physiological processes. Using primarily genetic screenings [73-77] as well as transcriptomics, miRNA deregulation analysis, and whole exome sequencing, many other genes have been shown to contribute to a senescence-like phenotype including PGM, IGFBP3 and IGFBPrP1], PAI-1, MKK3, MKK6, Smurf2, HIC-5, TBX2, BCL6, DRIL1, SAHH, PPP1A, Spn, KLF4, and CXCR2-binding chemokines, ([78] and references therein). Interestingly, all of these genes have been shown to be related to human tumorigenesis.

In conclusion, there are many regulators of senescence and many more to be discovered, and alterations to these regulators might render cells immortal and therefore allow carcinogenesis. Thus, the full panel of molecular alterations induced by carcinogens should be studied. Furthermore, compounds targeting these proteins and providing cellular immortalization without leaving a structural or epigenetic footprint may exist. In this case, the design of more specific and physiological assays may be necessary to determine the relevance of environmental compounds that may alter the senescence program and decisively contribute to immortalization and tumorigenesis.

\section{Acknowledgements}

The AC laboratory was supported by grants from the Spanish Ministry of Economy and Competitivity, ISCIII (Fis: PI12/00137, RTICC: RD12/0036/0028), Consejeria de Ciencia e Innovacion (CTS-6844) and Consejeria de Salud of the Junta de Andalucia (PI-0135-2010 and PI-0306-2012).

\section{References}

1. Farber E, Rubin H (1991) Cellular adaptation in the origin and development of cancer. Cancer Res 51: 2751-2761.

2. Farber E, Cameron R (1980) The sequential analysis of cancer development Adv Cancer Res 31: 125-226.

3. Thomas L, Lawrence SH (ed.) (1959) Discussion in Cellular and humoral aspects of hypersensitivity. 529-532.

4. Prehn RT (1976) Tumor progression and homeostasis. Adv Cancer Res 23 203-236.

5. Alsabti EA (1979) Tumor dormancy: a review. J Cancer Res Clin Oncol 95 209-220.

6. Hanahan D, Weinberg RA (2000) The hallmarks of cancer. Cell 100: 57-70.

7. Hanahan D, Weinberg RA (2011) Hallmarks of cancer: the next generation Cell 144: 646-674.

8. Farber E (ed.) (1976) The pathology of experimental liver cell cancer. Elsevier/ North Holland biomedical press, Amsterdam, The Netherlands.

9. Carbone M, Pass HI (2004) Multistep and multifactorial carcinogenesis: when does a contributing factor become a carcinogen? Semin Cancer Biol 14: 399405

10. Haddow A (1950) The chemotherapy of cancer. Br Med J 2: 1271-1272.

11. Farber E (1990) Clonal adaptation during carcinogenesis. Biochem Pharmacol 39: $1837-1846$

12. Foulds $L$ (1965) Multiple etiologic factors in neoplastic development. Cancer Res 25: 1339-1347.

13. Chen QM (2000) Replicative senescence and oxidant-induced premature senescence. Beyond the control of cell cycle checkpoints. Ann N Y Acad Sci 908: 111-125.
14. Liochev SI (2013) Reactive oxygen species and the free radical theory of aging Free Radic Biol Med 60: 1-4.

15. Colavitti R, Finkel T (2005) Reactive oxygen species as mediators of cellular senescence. IUBMB Life 57: 277-281.

16. Bertram C, Hass R (2008) Cellular responses to reactive oxygen speciesinduced DNA damage and aging. Biol Chem 389: 211-220.

17. Roninson IB (2003) Tumor cell senescence in cancer treatment. Cancer Res 63: $2705-2715$.

18. Chang BD, Broude EV, Dokmanovic M, Zhu H, Ruth A et al. (1999) A senescence-like phenotype distinguishes tumor cells that undergo terminal proliferation arrest after exposure to anticancer agents. Cancer Res 59: 37613767.

19. Wang X, Wong SC, Pan J, Tsao SW, Fung KH, et al. (1998) Evidence of cisplatin-induced senescent-like growth arrest in nasopharyngeal carcinoma cells. Cancer Res 58: 5019-5022.

20. Yeo EJ, Hwang YC, Kang CM, Kim IH, Kim DI, et al. (2000) Senescence-like changes induced by hydroxyurea in human diploid fibroblasts. Exp Gerontol 35: 553-571.

21. Michishita E, Nakabayashi K, Suzuki T, Kaul SC, Ogino H, et al. (1999) 5 -Bromodeoxyuridine induces senescence-like phenomena in mammalian cells regardless of cell type or species. J Biochem 126: 1052-1059.

22. Chang BD, Xuan Y, Broude EV, Zhu H, Schott B, et al. (1999) Role of p53 and p21waf1/cip1 in senescence-like terminal proliferation arrest induced in human tumor cells by chemotherapeutic drugs. Oncogene 18: 4808-4818.

23. te Poele RH, Okorokov AL, Jardine L, Cummings J, Joel SP (2002) DNA damage is able to induce senescence in tumor cells in vitro and in vivo. Cancer Res 62: 1876-1883.

24. Schmitt CA, Fridman JS, Yang M, Lee S, Baranov E, et al. (2002) A senescence program controlled by $\mathrm{p} 53$ and p16INK4a contributes to the outcome of cancer therapy. Cell 109: 335-346.

25. Roninson IB (2002) Tumor senescence as a determinant of drug response in vivo. Drug Resist Updat 5: 204-208.

26. Newbold RF, Overell RW, Connell JR (1982) Induction of immortality is an early event in malignant transformation of mammalian cells by carcinogens. Nature 299: 633-635.

27. Newbold RF, Overell RW (1983) Fibroblast immortality is a prerequisite for transformation by EJ c-Ha-ras oncogene. Nature 304: 648-651.

28. Yasaei H, Gilham E, Pickles JC, Roberts TP, O'Donovan M et al. (2013) Carcinogen-specific mutational and epigenetic alterations in INK4A, INK4B and p53 tumour-suppressor genes drive induced senescence bypass in normal diploid mammalian cells. Oncogene 32: 171-179.

29. Huang J, Plass C, Gerhauser C (2011) Cancer chemoprevention by targeting the epigenome. Curr Drug Targets 12: 1925-1956.

30. Shay JW, Roninson IB (2004) Hallmarks of senescence in carcinogenesis and cancer therapy. Oncogene 23: 2919-2933.

31. Duan J, Duan J, Zhang Z, Tong T (2005) Irreversible cellular senescence induced by prolonged exposure to $\mathrm{H} 2 \mathrm{O} 2$ involves DNA-damage-and-repair genes and telomere shortening. Int J Biochem Cell Biol 37: 1407-1420.

32. Terao Y, Nishida J, Horiuchi S, Rong F, Ueoka Y, et al. (2001) Sodium butyrate induces growth arrest and senescence-like phenotypes in gynecologic cancer cells. Int J Cancer 94: 257-267.

33. Christov KT, Shilkaitis AL, Kim ES, Steele VE, Lubet RA(2003) Chemopreventive agents induce a senescence-like phenotype in rat mammary tumours. Eur J Cancer 39: 230-239.

34. Wainwright LJ, Lasorella A, lavarone A (2001) Distinct mechanisms of cell cycle arrest control the decision between differentiation and senescence in human neuroblastoma cells. Proc Natl Acad Sci U S A 98: 9396-9400.

35. Carnero A (2013) Markers of cellular senescence. Methods Mol Biol 965: 63-81.

36. Rodier F, Campisi J (2011) Four faces of cellular senescence. J Cell Biol 192 547-556.

37. Coppé JP, Desprez PY, Krtolica A, Campisi J (2010) The senescenceassociated secretory phenotype: the dark side of tumor suppression. Annu Rev Pathol 5: 99-118. 
Citation: Vergel MDM, Carnero A (2014) Cellular Senescence as a Barrier to Environmental Carcinogenesis. J Carcinog Mutagen S3: 004. doi:10.4172/2157-2518.S3-004

38. Barrett JC, Annab LA, Alcorta D, Preston G, Vojta P, et al. (1994) Cellular senescence and cancer. Cold Spring Harb Symp Quant Biol 59: 411-418.

39. Serrano M, Blasco MA (2001) Putting the stress on senescence. Curr Opin Cell Biol 13: 748-753.

40. Sharpless NE, DePinho RA (2004) Telomeres, stem cells, senescence, and cancer. J Clin Invest 113: 160-168

41. Serrano M, Lin AW, McCurrach ME, Beach D, Lowe SW (1997) Oncogenic ras provokes premature cell senescence associated with accumulation of p53 and p16INK4a. Cell 88: 593-602.

42. Vergel M, Marin JJ, Estevez P, Carnero A (2010) Cellular senescence as a target in cancer control. J Aging Res 2011: 725365

43. Ben-Porath I, Weinberg RA (2005) The signals and pathways activating cellular senescence. Int J Biochem Cell Biol 37: 961-976.

44. Collado M, Gil J, Efeyan A, Guerra C, Schuhmacher AJ, et al. (2005) Tumour biology: senescence in premalignant tumours. Nature 436: 642 .

45. Chen Z, Trotman LC, Shaffer D, Lin HK, Dotan ZA, et al. (2005) Crucial role of p53-dependent cellular senescence in suppression of Pten-deficient tumorigenesis. Nature 436: 725-730.

46. Michaloglou C, Vredeveld LC, Soengas MS, Denoyelle C, Kuilman T, et al (2005) BRAFE600-associated senescence-like cell cycle arrest of human naevi. Nature 436: 720-724

47. Narlik-Grassow M, Blanco-Aparicio C, Cecilia Y, Perez M, Muñoz-Galvan S, et al. (2013) Conditional transgenic expression of PIM1 kinase in prostate induces inflammation-dependent neoplasia. PLoS One 8: e60277.

48. Baudino TA, Maclean KH, Brennan J, Parganas E, Yang C, et al. (2003) Myc-mediated proliferation and lymphomagenesis, but not apoptosis, are compromised by E2f1 loss. Mol Cell 11: 905-914.

49. Schmitt CA, Fridman JS, Yang M, Baranov E, Hoffman RM, et al. (2002) Dissecting p53 tumor suppressor functions in vivo. Cancer Cell 1: 289-298.

50. Carnero A, Lleonart ME (2011) Epigenetic mechanisms in senescence, immortalisation and cancer. Biol Rev Camb Philos Soc 86: 443-455.

51. Feliciano A, Sánchez-Sendra B, Kondoh H, Lleonart ME (2011) MicroRNAs Regulate Key Effector Pathways of Senescence. J Aging Res 2011: 205378.

52. Olovnikov AM (1996) Telomeres, telomerase, and aging: origin of the theory Exp Gerontol 31: 443-448.

53. Campisi J, d'Adda di Fagagna F (2007) Cellular senescence: when bad things happen to good cells. Nat Rev Mol Cell Biol 8: 729-740.

54. Carnero A, Link W, Martinez JF, Renner O, Castro ME, et al. (2003) Cellular Senescence and Cancer. Res Adv Cancer 3: 183-198.

55. Sherr CJ, McCormick F (2002) The RB and p53 pathways in cancer. Cancer Cell 2: 103-112.

56. Ohtani N, Yamakoshi K, Takahashi A, Hara E (2004) The p16INK4a-RB pathway: molecular link between cellular senescence and tumor suppression. J Med Invest 51: 146-153.

57. Zanella F, Link W, Carnero A (2010) Understanding FOXO, new views on old transcription factors. Curr Cancer Drug Targets 10: 135-146.

58. Blagosklonny MV (2008) Prevention of cancer by inhibiting aging. Cancer Bio Ther 7: 1520-1524
59. Blagosklonny MV (2013) Hypoxia, MTOR and autophagy: converging on senescence or quiescence. Autophagy 9: 260-262.

60. Castro ME, Ferrer I, Cascón A, Guijarro MV, Lleonart M, et al. (2008) PPP1CA contributes to the senescence program induced by oncogenic Ras. Carcinogenesis 29: 491-499.

61. Ruiz L, Traskine M, Ferrer I, Castro E, Leal JF, et al. (2008) Characterization of the p53 response to oncogene-induced senescence. PLoS One 3: e3230.

62. Narita M, Lowe SW (2004) Executing cell senescence. Cell Cycle 3: 244-246.

63. Demidenko ZN, Blagosklonny MV (2008) Growth stimulation leads to cellular senescence when the cell cycle is blocked. Cell Cycle 7: 3355-3361.

64. Narita M, Nũnez S, Heard E, Narita M, Lin AW, et al. (2003) Rb-mediated heterochromatin formation and silencing of E2F target genes during cellular senescence. Cell 113: 703-716.

65. Hahn WC, Counter CM, Lundberg AS, Beijersbergen RL, Brooks MW, et al. (1999) Creation of human tumour cells with defined genetic elements. Nature 400: 464-468.

66. Qian Y, Chen X (2013) Senescence regulation by the p53 protein family Methods Mol Biol 965: 37-61.

67. Wadhwa R, Sugihara T, Taira K, Kaul SC (2004) The ARF-p53 senescence pathway in mouse and human cells. Histol Histopathol 19: 311-316.

68. Wynford-Thomas D (1996) p53: guardian of cellular senescence. J Pathol 180 118-121.

69. Thomas DM, Yang HS, Alexander K, Hinds PW (2003) Role of the retinoblastoma protein in differentiation and senescence. Cancer Biol Ther 2: 124-130.

70. Ferrer I, Blanco-Aparicio C, Peregrina S, Cañamero M, Fominaya J, et al. (2011) Spinophilin acts as a tumor suppressor by regulating $\mathrm{Rb}$ phosphorylation. Cell Cycle 10: 2751-2762.

71. Calnan DR, Brunet A (2008) The FoxO code. Oncogene 27: 2276-2288.

72. Greer EL, Brunet $A(2008)$ FOXO transcription factors in ageing and cancer Acta Physiol (Oxf) 192: 19-28.

73. Leal JF, Fominaya J, Cascón A, Guijarro MV, Blanco-Aparicio C, et al. (2008) Cellular senescence bypass screen identifies new putative tumor suppressor genes. Oncogene 27: 1961-1970.

74. Marasa BS, Srikantan S, Masuda K, Abdelmohsen K, Kuwano Y, et al. (2009) Increased MKK4 abundance with replicative senescence is linked to the joint reduction of multiple microRNAs. Sci Signal 2: ra69.

75. Kortlever RM, Higgins PJ, Bernards R (2006) Plasminogen activator inhibitor-1 is a critical downstream target of p53 in the induction of replicative senescence. Nat Cell Biol 8: 877-884.

76. Peeper DS, Shvarts A, Brummelkamp T, Douma S, Koh EY, et al. (2002) A functional screen identifies hDRIL1 as an oncogene that rescues RAS-induced senescence. Nat Cell Biol 4: 148-153.

77. Shvarts A, Brummelkamp TR, Scheeren F, Koh E, Daley GQ, et al. (2002) A senescence rescue screen identifies BCL6 as an inhibitor of anti-proliferative p19(ARF)-p53 signaling. Genes Dev 16: 681-686.

78. Vergel M, Carnero A (2010) Bypassing cellular senescence by genetic screening tools. Clin Transl Oncol 12: 410-417.
This article was originally published in a special issue, DNA damage/ repair: Mutagenesis : Carcinogenesis handled by Editor(s). Dr. Lubomir Manolov Stoilov, University: Institute of Genetics, Bulgaria; Dr. Kandace Jo Williams, University of Toledo College of Medicine, USA; Dr. Mu Wang, Indiana University School of Medicine, USA
Citation: Vergel MDM, Carnero A (2014) Cellular Senescence as a Barrier to Environmental Carcinogenesis. J Carcinog Mutagen S3: 004 doi:10.4172/21572518.S3-004 